\title{
Analysis of Hydrogen Production Potential Based on Resources Situation in China
}

\author{
Yanmei Yang*, Geng Wang, Ling Lin, and Sinan Zhang \\ China National Institute of Standardization, Beijing, China
}

\begin{abstract}
Hydrogen energy is becoming more and more blooming because of its diversified sources, ecofriendly and green, easy storage and transportation, high-efficient utilization, etc. The use of hydrogen as an energy carrier is expected to grow over the next decades. Hydrogen, like electricity, is a secondary energy. Hydrogen production is the foundation for all kinds of applications. Based on the resources situation in China, potential of hydrogen production is analysed. China has a large potential of hydrogen production from coal, which is about 2.438 billion tons. Potential of hydrogen production from natural gas is less than that from coal, which is about 501 million tons. According to the average consumption of methanol per year, potential of hydrogen production from methanol is about 690,000 tons per year. Potential of hydrogen production from industrial gas (coking, petrochemical and chlor-alkali industries) is about 866,400 tons per year. Potential of hydrogen production from abandoned renewable energy power is about 1798.2 million tons per year. Distribution of resources in China differs among provinces. The deployment of hydrogen industry should pay attention to local hydrogen production potential. A green hydrogen production method, such as water electrolysis by renewable energy power, is a promising and environmental friendly way.
\end{abstract}

\section{Introduction}

Hydrogen energy is becoming more and more blooming because of its diversified sources, eco-friendly and green, easy storage and transportation, high-efficient utilization, etc. In recent years, many countries, especially developed countries, have included the deployment of hydrogen energy as a part of their national energy strategy ${ }^{[1,2]}$. China has also clearly stipulated in many important documents to vigorously develop the hydrogen energy industry. There are 25 cities that have deployed hydrogen energy industry in China. Hydrogen fuel cell vehicles, like buses and logistics vehicles, have been operated for demonstration in Foshan, Shanghai, Zhangjiakou, etc.

Hydrogen energy, like electricity, is a secondary energy, which is not available in nature. It can be produced by using diverse resources, including fossil fuels (such as coal, natural gas and methanol) and renewable energy (such as biomass, solar, wind and hydro-electric power).

Resources in China is characterised as rich coal, lean oil and little gas ${ }^{[3]}$. Based on the resources situation, hydrogen production by coal gasification, steam methane reforming, water electrolysis and purification of industrial gas is analysed in this paper. Considering hydrogen energy demand, suggestions for options of hydrogen production methods are proposed.

\section{Hydrogen production methods}

There are many process for hydrogen production, including conventional and alternative energy resources. For a long time, hydrogen has been used in chemical, metallurgical, food industries. As is reported, hydrogen production in China is about 21 million tons in 2016. Figure 1 shows the combination of resources for hydrogen production. Around $96 \%$ of the global hydrogen production is generated from fossil fuels, including 48\% from natural gas, 30\% from hydrocarbons and alcohols, and 18\% from coal. Hydrogen production from water electrolysis only accounts for about $4 \%$. However, in China, structure of hydrogen production is different from the global average. In China, about $62 \%$ of hydrogen production is generated from coal, and about $19 \%$ of hydrogen production is generated from natural gas. Hydrogen production by water electrolysis only accounts for about $1 \%$.
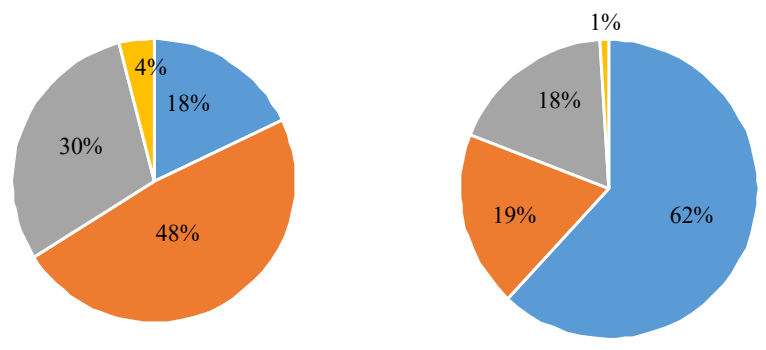

coal $\square$ natural gas $\square$ hydrocarbons \& alcohols $\square$ water electrolysis
(a) global average
(b) China

Fig. 1. Combination of Resources for Hydrogen Production ${ }^{[4]}$

\footnotetext{
* Corresponding author: yangym@cnis.ac.cn
} 


\section{Analysis of hydrogen production}

Coal gasification and steam reforming of natural gas are the main methods of hydrogen production in China. Moreover, water electrolysis by wind-power, solarpower and hydro-power is a promising way to produce green hydrogen.

\subsection{Coal gasification}

Figure 2 is a typical process of hydrogen production by coal gasification, including coal or char gasification with steam or oxygen, desulfurization, shift conversion and purification.

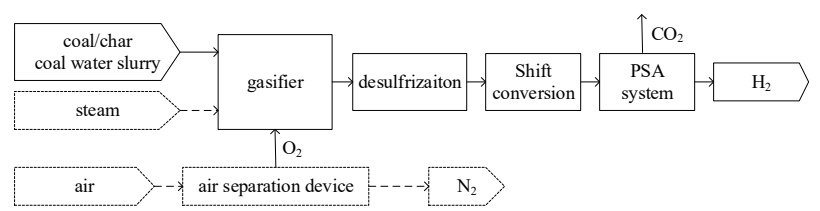

Fig. 2. Process of Hydrogen Production by Coal Gasification

China has abundant coal resources. Coalfield geological survey results show that total amount of prospective coal resources in China is 5.82 trillion tons. Now, the cumulative proven reserves are 2.01 trillion tons, and the reserves are about 1.95 trillion tons ${ }^{[5]}$.

It takes $8 \mathrm{~kg}$ coal to produce about $1 \mathrm{~kg}$ hydrogen gas. Assuming that $1 \%$ of China's coal resources are used for hydrogen production by coal gasification, the potential of hydrogen production from coal is about 2.438 billion tons.

Potential of hydrogen production based on coal reserves differs among different provinces. Mainly domestic coals are distributed in Shanxi, Shaanxi, Inner Mongolia, Ningxia, Xinjiang, Huanghuaihai district and Southwest China, only a small amount distributes in Southeast China. As a result, coal-rich district has a much higher potential of hydrogen production than the coal-lean district. The potential of hydrogen production based on domestic coal reserves is shown in Figure 3.

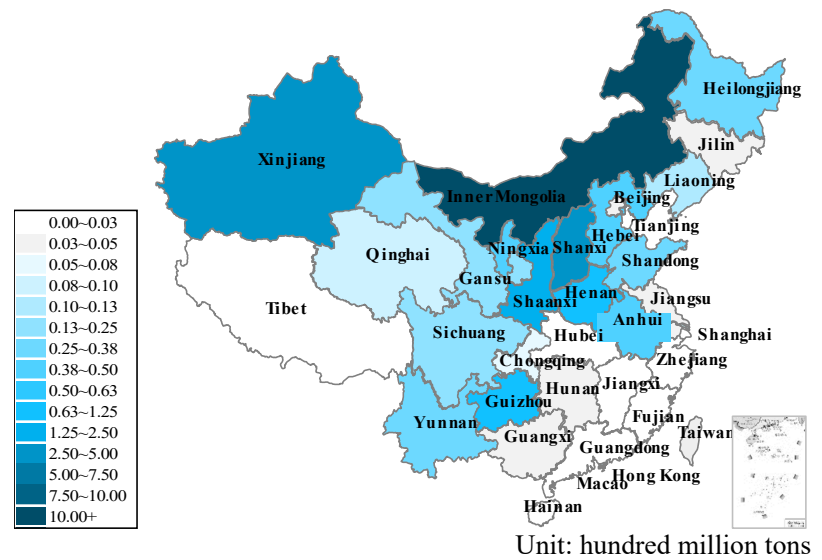

Fig. 3. Potential of Hydrogen Production Based on Coal Reserves

\subsection{Steam reforming of natural gas}

Figure 4 is a typical process of hydrogen production by steam reforming of natural gas, including desulfurization, reforming reaction, shift conversion and purification.

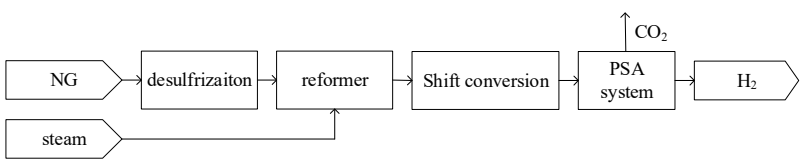

Fig. 4. Process of Hydrogen Production by Steam Reforming of Natural Gas

China has a relatively scarce natural gas reserves. The geological reserves of natural gas in China are 90.3 trillion cubic meters and the recoverable reserves are 50.1 trillion cubic meters ${ }^{[6]}$. Domestic natural gas resources are mainly distributed in the central part, western part and offshore areas, including Sichuan Basin, Ordos Basin, Tarim Basin, Qaidam Basin, Junggar Basin, Bohai Bay Basin, Qiongdongnan Basin, etc.

It takes $5 \mathrm{Nm}^{3}$ natural gas to produce about $1 \mathrm{~kg}$ hydrogen gas. Assuming that $5 \%$ of China's recoverable natural gas resources are used for steam reforming of natural gas to produce hydrogen, the potential of hydrogen production from natural gas is about 501 million tons.

\subsection{Reforming of methanol}

Figure 5 is a typical process of hydrogen production by reforming of methanol, including mixing system, reforming reaction and purification.

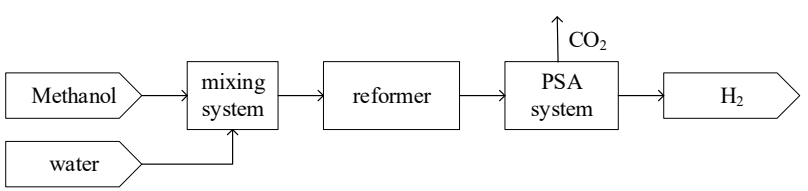

Fig. 5. Process of Hydrogen Production by Reforming of Methanol

As is shown in Figure 6, the consumption of methanol in China is about 50 million tons per year. It takes $7.2 \mathrm{~kg}$ methanol to produce about $1 \mathrm{~kg}$ hydrogen gas. Assuming that $1 \%$ of the consumption of methanol are used to produce hydrogen by reforming of methanol, the potential of hydrogen production from methanol is about 690,000 tons per year.

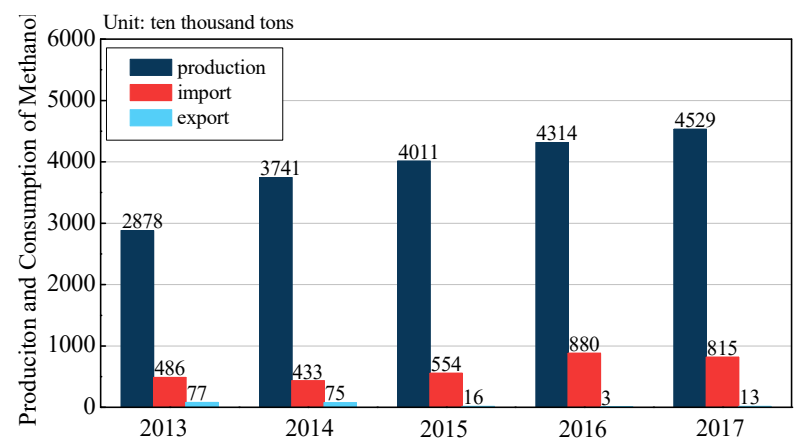

Fig. 6. Production and Consumption of Methanol in China ${ }^{[4]}$ 


\subsection{Hydrogen-rich industrial gas}

Hydrogen-rich gases are mainly distributed in coking, petrochemical, chlor-alkali industries, etc. Recovering and utilizing hydrogen from industrial gas can not only improve the comprehensive utilization efficiency of resources and promote economic benefits, but also reduce air pollution and protect the environment.

China is a big country in coke production and consumption. Coke industry is mainly distributed in Shanxi, Hebei, Shaanxi, Shandong, Inner Mongolia, Henan, Liaoning, Jiangsu and other regions. Coke production process produces a large amount of coke oven gas. It is estimated that producing one ton of coke can generate about $400 \mathrm{Nm}^{3}$ coke oven gas. According to the coke production in 2017, the coke oven gas production is about 172.4 billion $\mathrm{Nm}^{3}$. Assuming that hydrogen content in coke oven gas is about $40 \%$, the efficiency of PSA is $92 \%$ and $10 \%$ of the coke oven gas is recovered, the potential of hydrogen production from coking industry is about 566,400 tons per year. Hydrogen production potential based on distribution of cock industry is shown in Figure 7.

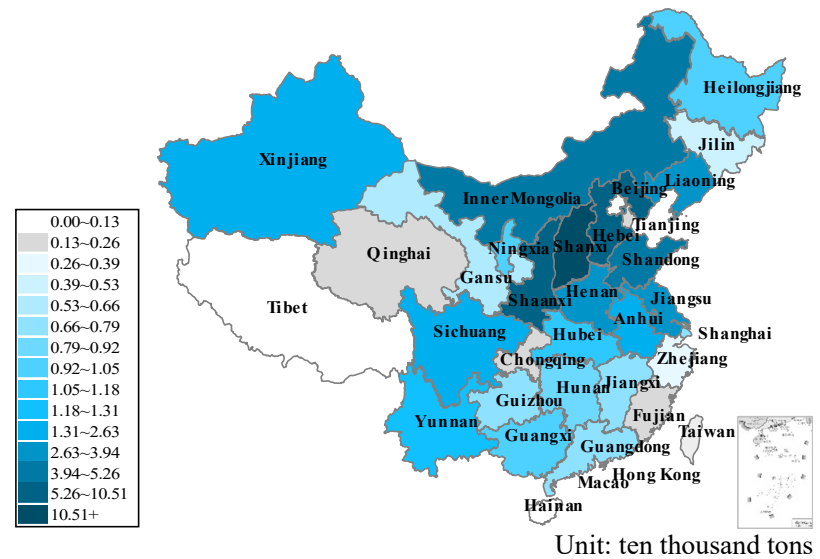

Fig. 7. Potential of Hydrogen Production Based on Coke Oven Gas

Propane dehydrogenation (PDH) is one of the production routes of propylene. It is reported that total production capacity of propylene in China is 5.14 million tons per year, mainly distributed in Shandong, Zhejiang, Tianjin, Jiangsu and Hebei.

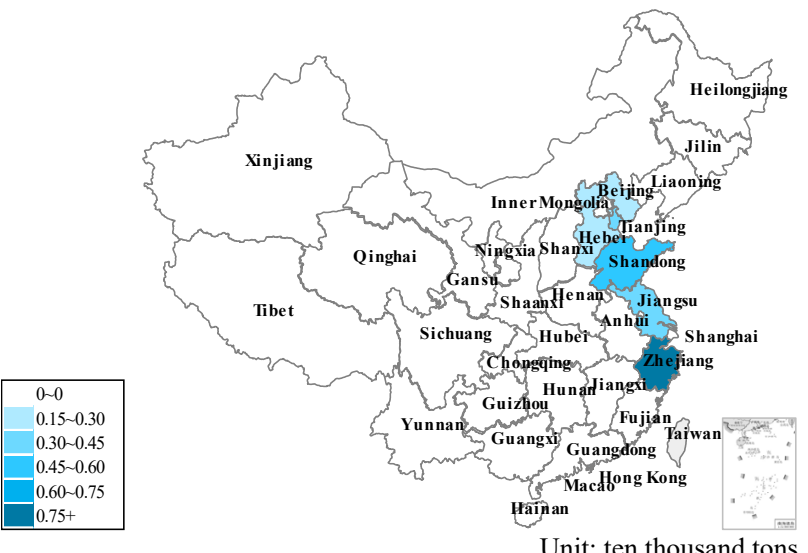

According to the theoretical calculation, producing one ton of propylene will eliminate $47.26 \mathrm{~kg}$ hydrogen gas. Assuming that all existing PDH units are put into operation at full load, efficiency of PSA is $92 \%$ and $10 \%$ of gas produced by PDH is used, the potential of hydrogen production from PHD industry is about 225,000 tons per year. Hydrogen production potential based on distribution of PDH industry is shown in Figure 8.

Chlor-alkali industry refers to the production of caustic soda, chlorine and hydrogen by electrolysis of salt water. In recent years, the annual production of caustic soda in China is about 30 -33 million tons, mainly distributed in Shandong, Jiangsu, Inner Mongolia, Xinjiang, Zhejiang, Henan and Hebei. Utilization of hydrogen in chlor-alkali industry includes two ways: on the one hand, hydrogen reacts with chlorine to produce hydrochloric acid, on the other hand, hydrogen is used to produce chemicals such as hydrogen peroxide or direct combustion. According to theoretical calculation, producing one ton of caustic soda will generate $25 \mathrm{~kg}$ hydrogen gas. Assuming that the production of caustic soda is 30 million tons per year and emission rate of chlor-alkali industry is $10 \%$, the potential of hydrogen production from chlor-alkali industry is about 75,000 tons per year. Hydrogen production potential based on distribution of chlor-alkali industry is shown in Figure 9.

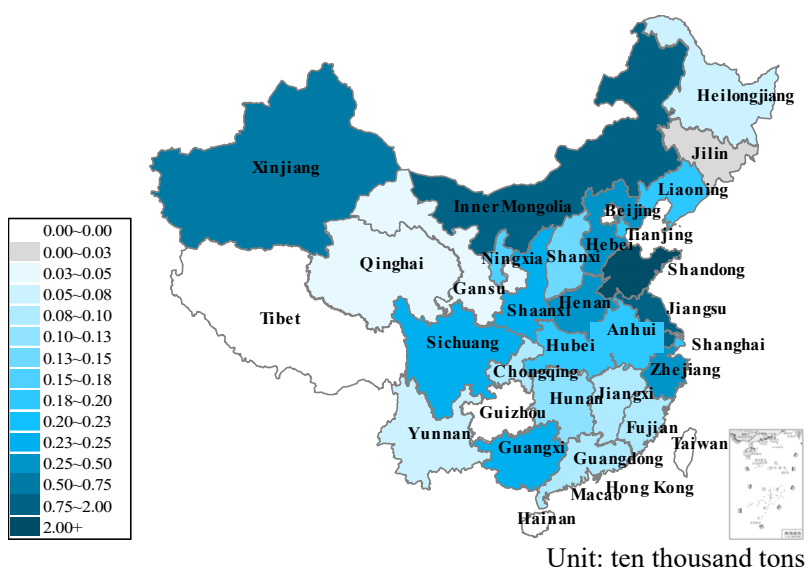

Fig. 9. Potential of Hydrogen Production Based on Chlor-alkali industry

\subsection{Water electrolysis}

Hydrogen production by water electrolysis is an inverse process of fuel cell reaction, that is, hydrogen generation on cathode and oxygen generation on anode by water electrolysis. Electrolyser is the central equipment of hydrogen production by water electrolysis. At present, there are roughly three types of electrolysers: alkaline electrolyser, proton exchange membrane (PEM) electrolyser and solid oxide electrolyser (SOE). Figure 10 is a typical process of hydrogen production by water electrolysis, including liquid mixing, electrolysis and gas-liquid separation.

Fig. 8. Potential of Hydrogen Production Based on PDH 


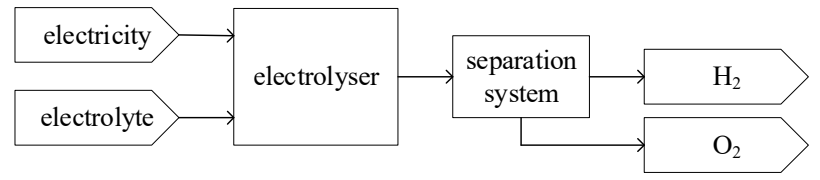

Fig. 10. Process of Hydrogen Production by Water Electrolysis

In recent years, the scale of hydro-power, wind power, solar power generation in China has gradually increased. Hydrogen production by water electrolysis with the use of renewable energy is a near-zero carbon emission hydrogen production method. Besides, it is also an effective energy storage method, which can improve the utilization of renewable energy. Figure 11 shows the distribution of installed renewable energy power generation.

As is reported, in 2017, abandoned hydropower in China is 51.5 billion kilowatt-hours, including 15.6 billion kilowatt-hours in Sichuan and 29 billion kilowatthours in Yunnan. Abandoned wind power in China is 41.9 billion kilowatt-hours, including 13.25 billion kilowatt-hours in Xinjiang, 2.03 billion kilowatt-hours in Heibei and 200 million kilowatt-hours in Shaanxi. Abandoned solar power is 7.3 billion kilowatt-hours. Total amount of abandoned soalr power in Shaanxi, Gansu, Qinghai, Ningxia and Xinjiang is 6.67 billion kilowatt-hours. Assuming that energy consumption of water electrolyser is $5 \mathrm{kWh} / \mathrm{Nm}^{3} \mathrm{H}_{2}, 1798.2$ million tons of hydrogen can be produced by abandoned renwable energy power in 2017.

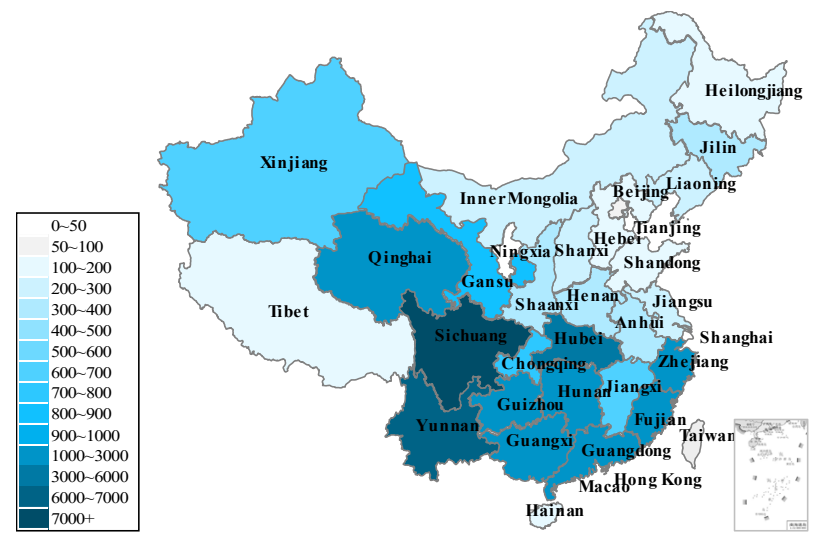

(a) hydro-power

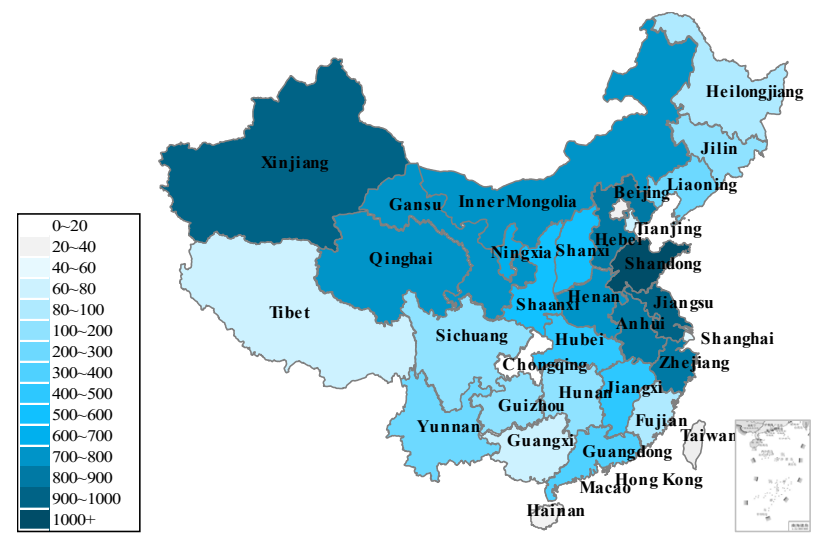

(b) solar-power

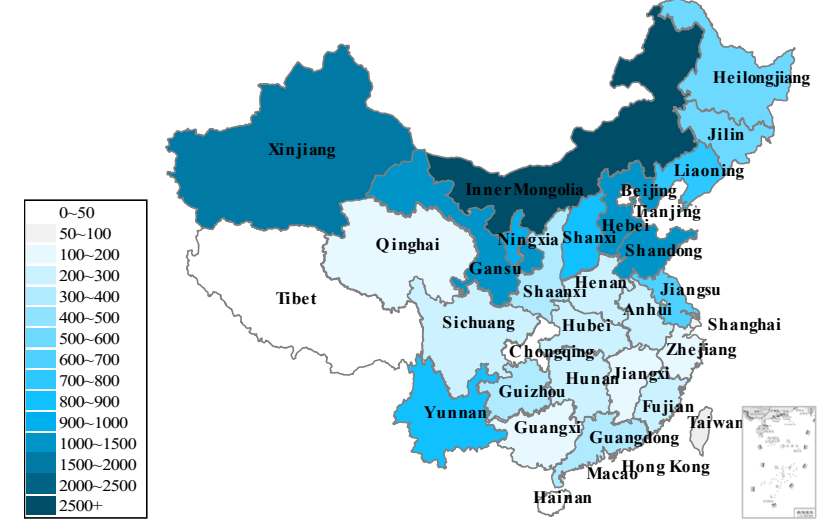

(c) wind-power

Unit: ten thousand $\mathrm{kWh}$

Fig. 11. Distribution of Installed Renewable Energy Power Generation [7]

\subsection{Other production methods}

Other hydrogen production methods, such as photolysis and fermentation are in development and demonstration. With near-zero emission in the production process, these are promising methods for the production of green hydrogen ${ }^{[8]}$.

\section{Conclusions}

Based on the resources situation in China, potential of hydrogen production is analysed. Concluding remarks are as follows:

(1) China has a large potential of hydrogen production from coal, which is about 2.438 billion tons.

(2) Potential of hydrogen production from natural gas is less than that from coal, which is about 501 million tons.

(3) According to the average consumption of methanol per year, potential of hydrogen production from methanol is about 690,000 tons per year.

(4) Potential of hydrogen production from industrial gas (coking, petrochemical and chlor-alkali industries) is about 866,400 tons per year, including 566,400 tons from coke oven gas, 225,000 tons from PDH industry and 75,000 tons from chlor-alkali industry.

(5) Potential of hydrogen production from abandoned renewable energy power is about 1798.2 million tons per year.

(6) Distribution of resources in China differs among provinces. The deployment of hydrogen industry should pay attention to local hydrogen production potential. A green hydrogen production method, such as water electrolysis by renewable energy power, is a promising and environmental friendly way.

\section{References}

1. Hydrogen Council. Hydrogen scaling up - a sustainable pathway for the global energy transition (2017). 
2. J. D. Holladay, J. Hu, D. L. King, Y. Wang, Catalysis Today 13917 (2009)

3. K. Xie, W. Li, W. Zhao, Energy 35, 7 (2009)

4. China National Instititue of Standardizaiton. Blue book for infrastructure development of hydrogen industry in China (2018)

5. J. Shu, China Coal Daily (2018)

6. Ministry of Land and Resources, National Dynamic Evaluation of Oil and Gas Resources (2015)

7. China Electric Power Enterprise Federation. Annual Development Report of China Electric Power Industry (2018)

8. P. Nikolaidis, A. Poullikkas, Renewable and Sustainable Energy Reviews 67, 5(2017) 